\title{
Editorial: A WISC is Never Enough!
}

Welcome to the first issue of our journal under the new title Journal of Psychologists and Counsellors in Schools. This issue is a special one on psycho-educational assessment. We have a range of interesting and stimulating articles on this topic, reflecting the important and substantial role that assessment plays in the work of many school psychologists and counsellors. Psycho-educational assessment includes areas such as behavioural, social-emotional and vocational assessment, although most referrals for assessment in schools are related to learning difficulties. The issue has a truly international flavour, with authors from Australia, Greece, China, Ireland, Bangladesh, Peru, Iran and the United States.

I have titled this editorial 'A WISC is Never Enough' because it seems that when people think about psycho-educational assessment, the WISC is the first thing that comes to mind, and indeed sometimes the only thing that comes to mind! But, on its own, a WISC assessment is rarely sufficient to provide understanding of a child's abilities and the factors that are influencing learning. In addition, the WISC is not necessarily the best measure of intellectual assessment for every child. Alternative instruments such as the Stanford Binet, Woodcock Johnson, or non-verbal tests are sometimes more appropriate. Yet, as the first article by John Meteyard and myself in this special issue shows, the WISC is very heavily used by Australian practitioners in the assessment of students with learning difficulties. Alternative measures of intelligence are used much less frequently and, surprisingly, tests of learning, memory and phonological skills are not commonly administered either.

The situation in the Republic of Ireland is considered in the following paper. Emma Harkin, Alison Doyle and Conor McGuckin describe the screening assessments that are used to identify learning disabilities in higher education. Interestingly, they found little consistency in testing practices across their sample of universities, colleges and institutes. The focus of most was on reading disability (dyslexia) only, rather than more comprehensively on disabilities such as dyscalculia, dysgraphia, dyspraxia, and attention disorders. To achieve uniformity in screening procedures, and thus greater equity for students, the researchers recommend practice guidelines and a standard battery of comprehensive and rigorous tests.

The next article by Anastasia Alevriadou and Stergiani Giaouri draws attention to a group of students whose learning difficulties may not be easily recognised or understood in the classroom: those who, despite average reading skills, have a disorder of written expression known as dysgraphia. As the researchers point out, writing is a very complex endeavour that makes significant demands on executive functioning skills such as planning and monitoring. Their findings from a study of the relationship between written expression and executive functioning suggest that 
problems with executive functioning represent a risk factor for writing difficulties. Early interventions that focus on metacognitive and self-regulatory strategies such as goal-setting and self-monitoring are thus likely to be important for subsequent competence with written language.

Among the many challenges in psycho-educational assessment, report writing is often highlighted as the greatest headache for school psychologists and counsellors. As we all know, 4 to 6 hours of assessment may easily equate to 8 to 12 hours of report writing! Apart from the legal and ethical issues around accurate reporting of test results, reports are usually the most visible and enduring evidence of the quality of a practitioner's professional practice. Best practice involves not only accurate reporting of results, but also appropriate interpretations and integrations of all aspects of the assessment, including test behaviour, observations and informal assessments, with the aim of answering the referral question. Reflective practitioners tend to consider and reconsider aspects of report writing, such as the structure and language that they use. Janet Fletcher, Tara Hawkins and Jenna Thornton report on a study in which they investigated the reactions of psychologists and teachers to different report styles. Their conclusion that theme-based, non-technical reports are likely to be most effective provides valuable information to keep in mind when rethinking one's own style of report.

The next article takes a broader view of psycho-educational assessment, extending beyond the testing of intelligence, academic achievement, and aspects of functioning such as memory and attention. Sandra Prince-Embury describes the assessment of resilience, with particular reference to the Resiliency Scales for Children and Adolescents (RSCA). She highlights the importance of considering the risk and protective factors that may impact on a child's functioning in the school context. The RSCA can provide potentially useful evidence of students' self-reported approaches to learning, including their drive for mastery. Social connectedness and emotional reactivity (such as the ability to self-regulate emotional responses) are also assessed, given the demonstrated relevance of these constructs for student functioning and wellbeing.

Taking an even broader approach to psycho-educational assessment is the last article in the first section of this issue. Recently I visited Bhutan, a country where there are no psychologists, and came across an Australian Educational and Developmental Psychologist working in a school in the small capital city, Thimphu. Dr Angela James has been funded by the Australian Government through the Australian Red Cross to spend one year in a Thimphu school. Her role is to build capacity through increasing the awareness of school staff of a range of issues relevant to children's learning and development, and to create resources that will enable them to assess and respond to aspects of student functioning. Angela has no standardised tests in Bhutan and, even if she were to adapt Western tests, there are no Bhutanese psychologists who could administer them! Her challenge is to identify areas that are important to learning, that could be assessed by teachers or other school staff, and that would lead to appropriate interventions. Then she will develop appropriate measures and resources. Discussing these issues with Angela led me to reflect on the process of psycho-educational assessment. I suspect that at times assessment is undertaken more for the sake of assessing rather than for a clear purpose. Without a clear purpose and the likelihood that testing will achieve 
that purpose, assessment cannot be justified. Of course, assessment extends well beyond the use of standardised tests to include more creative and informal methods, although these too must be as purposeful and robust as possible.

In Australia, while we might not always have local norms for all the tests we use, we do have a wide range of well-developed instruments at our finger tips, and we have rigorous training courses, respected professional bodies, codes of ethics and professional standards. From my work in Bangladesh over the past few years, I have become aware of the difficulties psychologists face in less developed countries. To illustrate those difficulties, I invited colleagues Shaheen Islam in Bangladesh, Hui Su from China and Sharifeh Younesian in Iran to co-author the next article. The paper provides interesting information about the development of the profession of psychology and insights into the challenges facing psychologists in those countries, especially with respect to psycho-educational assessment. I hope it will not only increase your understanding of the profession in less developed countries, but also possibly stimulate your interest in collaborating with psychologists in parts of the world where professional training, resources and supports are so limited. You may even want to take over from Angela James in Bhutan, to continue her creative work in developing and implementing psycho-educational practices in a country where there currently are no psychologists.

Our section on applied practices is introduced by Editor Dr Susan Colmar and contains four articles about psycho-educational assessment that have particular relevance for practitioners. Finally, our book review section in this issue features two reviews of Jerome Sattler's recently updated text on assessment of children. Psychologists Santo Russo and Dr Jessica Paynter have each provided a comprehensive and critical review of this text that will be of considerable value to school psychologists and counsellors.

Our next issue in December will be a general one, containing articles across a range of areas relevant to school psychology and counselling. That will be followed in June 2016 by another special issue, this time on the topic of developmental disability. I would encourage you to consider submitting a paper for consideration in this special issue. We welcome submissions across a range of areas, including empirical research studies, articles about professional practice issues, critical literature reviews, case study reports, and evaluations of interventions. In the meantime, I hope you enjoy reading this current issue and that you find the articles to be of value for your practice of psycho-educational assessment.

Linda Gilmore

Guest Editor 